\title{
Allotropes of Fieldwork in Nanotechnology
}

\author{
Christopher Kelty
}

\begin{abstract}
This article discusses the distinctive contributions that the discipline of anthropology (in particular, socio-cultural anthropology) might make to the study of nanotechnology. It focuses on recent research conducted by anthropologists on the subject of nanotechnology, human health and the environment at the Center for Biological and Environmental Nanotechnology (CBEN) at Rice University. The chapter plays on the chemical concept of "allotropes" as a way of understanding three variations on the method of anthropological fieldwork. These allotropes of fieldwork include a focus on site, in this case CBEN; a focus on method, especially the role of observations, participation and objectivity; and a focus on substance, the subject matter of nano-science and technology, in this case water and its relationship to nano-materials. The argument of the paper is that all of these are necessary for effective ethnographic work and they can focus attention on the human practices that shape research, concepts and results in nanotechnology. It further argues that such practices go unnoticed, or are deliberately downplayed, by some nanoscientists and engineers, and so the contribution of anthropology can be to highlight certain critical projects or potential alternative futures not otherwise visible.
\end{abstract}

Keywords Anthropology, fieldwork, environment, human health, methodology

\begin{abstract}
Here's an example that hit me the other day at an NSF conference on directions for potable water treatment. So in the past, you would notice the water supply getting shorter and shorter and you'd say, well, we're going to treat dirtier and dirtier water. We'll take all this stuff out of it, we'll take the salts out of the ocean, we'll take all the crud out of wastewater and reuse the wastewater and so we're going to take stuff out of it and we're going to clean it up. And the nano vision of this is, you know, let's just make water. Let's just construct it from oxygen and hydrogen. I mean, that would be a very nano thing to do.
\end{abstract}

(Interview with Mark Wiesner, April 2004)

This chapter addresses two issues: first, it lays out some of the distinctive contributions that the discipline of anthropology (in particular, socio-cultural anthropology) might make to the study of nanotechnology and second, it touches on recent research conducted by anthropologists on the subject of nanotechnology, human health and the environment at the Center for Biological and Environmental Nanotechnology (CBEN)

Rice University

F. Jotterand (ed.) Emerging Conceptual, Ethical and Policy Issues in Bionanotechnology,

(C) Springer Science + Business Media B.V. 2008 
at Rice University. The chapter plays on the chemical concept of "allotropes" as a way of understanding how variations on the focus and meaning of ethnographic fieldwork amongst scientists and engineers should be used to reveal aspects of nanotechnology that are not rendered accessible in any other way. Each allotrope examines ethnographic fieldwork from a different organizing perspective. The first allotrope considers the site, in this case $\mathrm{CBEN}$, as that which organizes research; the second allotrope considers method as an organizing force; and the third allotrope looks at substance or subject matter as the organizing force. The argument of the paper is that all of these are necessary for effective ethnographic work to reveal something that is not already known by the actors, or obvious from a review of the literature. Effective anthropological fieldwork in areas of emerging science and technology can focus attention on the human practices that shape research, concepts and results, but go unnoticed, or are deliberately downplayed by scientists and engineers, and ultimately contribute to certain kinds of critical projects that emerge from within science.

\section{Allotropes of Fieldwork}

Among social science disciplines, it is fair to say that none is as ecumenical, pluralistic, and even internally contradictory as that of anthropology. Few other disciplines are at home researching everything from archaeological origins of complex society to cosmopolitanism in modern Greece; from primate genetics to sexual behavior among Indian trans-gendered prostitutes. The range of work brings with it a concomitant range of methodological tools and approaches, ranging from symbolic analysis to archaeological investigation to DNA sequencing and comparison. A key component present across many of these methods in anthropology, however, is fieldwork. Fieldwork encompasses participant-observation, interview and dialogue, collaboration and critique. It is as central, if not more, to the definition of anthropology as any theoretical concern with the human (anthropos).

Although this chapter consists primarily of socio-cultural anthropology with an emphasis on elites and contemporary complex societies, one might well imagine the various ways in which many of the sub-fields of anthropology could become interested in aspects of nanotechnology. Medical anthropologists (and especially bio-medical anthropologists studying contemporary high-tech medicine) might be interested in the emerging therapies for cancer that make use of gold nano-shells and nano-rods. Linguistic anthropologists interested in creolization or pidginzation should find a fascinating project for study in the attempt to forge new nomenclatures and standards for nano-scale particles and materials. Archaeologists who theorize about tool use might see something of value in the claims for "human enhancement" so often promised by nanotechnologists (see Stone, n.d.).

Fieldwork in anthropology thus has a variety of "allotropes" - to play on one of the key concepts in a basic understanding of nanotechnology. Allotropes are the diverse shapes a single element can take, depending on the arrangement of the bonds between the atoms. The resulting materials can have vastly different thermal, electrical and structural properties. Carbon, for example, has diamond, graphite, and buckminsterfullerenes 
(buckyballs) among its allotropes. If fieldwork is the "carbon" of anthropology, then its arrangement and structure can yield similarly diverse results, depending on the tools and techniques used - depending on whether questions are being answered or hypotheses generated, and on the length, locale, and style of interaction that is imagined (Marcus \& Fischer, 1986; Marcus, 1995, 1998; Gupta \& Ferguson, 1997, 2002). Without pushing the simile too far, these allotropes of fieldwork can in turn have very different properties; some fieldwork projects are extremely flexible and robust - engaged in a kind of studied curiosity without explicit questions. Others are rigidly defined, seeking "qualitative" answers through survey, interview or dialogue. The version of socio-cultural anthropology presented here is primarily focused on fieldwork that starts in medias res - especially among things that appear to be novel, surprising or emergent, such as nanotechnology. In this setting, one might organize one's fieldwork into one of three possible allotropes: site, method and substance.

The most obvious defining factor of fieldwork can be that of the site. Site can be a classical geographic locale - a village, a street corner, a café, a lab - but more often today it is defined with respect to some kind of conceptual object as well - state surveillance and policing, economic development or identity politics, for instance. Objects that travel are also common reference points - sacred objects, commodities and artworks; or more often, money, policies and legal documents. Site allows for a way of keeping track of connections and social actions that make up a particular problem area. However, it is also the case that there are frequently issues that impinge on one site, but are not easily visible within it - the most common such situation is the effects of global institutions, or global financial capitalism on the lives and work of local populations in specific local contexts. If site alone defines an anthropological project, then the demand for novelty in method and or substance is high, since there is little analytic depth in simply choosing a particular site.

A second mode of defining fieldwork is that of method. At a very basic level, method concerns the what, where, who, when, and why of field research. In closely bounded settings (a village, a bar or a lab) these are easier to define than in the changed global conditions within which most anthropologists must now operate - alongside experts and fellow social scientists whose goals are different in kind from those of the socio-cultural anthropologist. For instance, the manner in which an anthropologist looks at "the economy" is quite different from how an economist might; similarly, the mental life of individuals can be approached much differently by the symbolic anthropologist than the manner in which a psychologist or cognitive scientist might approach it; furthermore, the fact that these experts - economists and cognitive scientists, for instance - are the principal actors defining what economies and brains are, makes the work of the anthropologist doubly challenging. Method, in this context, consists of questioning the foundations not only of the discipline of anthropology, but those of other disciplines as well. This immodest approach is risky, needless to say, and usually requires a significant investment in time and learning to carry out. It also suggests that anthropology often, though not always, will take a position of critique vis-à-vis neighboring disciplines. If method is the defining focus of an anthropological project, sites and subjects are in danger of proliferating wildly.

Finally, substance can also define the structure of fieldwork. Substance suggests not simply a tangible substance, but the "subject matter" of a study. The "politics of oil and energy" for instance, might define a set of sites and methods for investigation; 
"human rights law" similarly might imply a number of possible sites and methods for achieving an anthropological understanding of the changing substance and definition of what counts as human and what as rights. By defining a topic in terms of substance, an anthropologist can avoid some of the traps of a too narrowly defined site-based project or too strictly defined a methodology, by being more flexible with respect to possible sites, people and forms of investigations. By the same token, a project defined only in terms of substance often faces the fact that other researchers in other disciplines have already staked out particular substances - and the question returns: what is distinctive about the anthropologist's observations?

In the remainder of this paper, I present each of the allotropes with respect to a project in the anthropology of nanotechnology. First, a description of the specific site within which the bulk of our research is carried out, and a detailed description of why the site is both distinctive and partially representative of emerging nanotechnology; second, a series of methodological approaches that can help orient the epistemological questions about the goal of an anthropology of nanotechnology; and third a focus on substance - in this case, water, and its relevance to nanotechnology - that has emerged by virtue of the combination of site and method.

\section{Allotrope: Site}

Rice University's Center for Biological and Environmental Nanotechnology (CBEN) was funded by the National Science Foundation in 2001, as part of the National Nanotechnology Initiative. Rice's presence in Nanotechnology has been significant given its small size (less than 4,000 graduate and undergraduate students and around 500 full-time faculty). This has been due in large part to the work of two committed Rice faculty; the scientific patron, recently deceased Nobel laureate Richard Smalley, and the political patron, former science adviser to Clinton, Neal Lane. Both men have been extremely well respected on campus, and have had signi-ficant influence over the direction of university vision and funding over the last 15 years.

The Center for Biological and Environmental Nanotechnology, however, is an unusual center for Rice to have - given the fact that Smalley, and many other campus scientists work primarily on the chemistry and engineering of fullerenes (especially buckminsterfullerenes, for which Smalley, Robert Curl and Harold Kroto were awarded the Nobel prize in 1996, and Single Walled Carbon Nanotubes, discovered in 1991). One might expect a center devoted to fullerene chemistry or the chemical engineering of nanotubes, or a center aimed specifically at contributions to the homegrown energy industry - not a center explicitly identified with the environment and biology.

CBEN was an idea hatched by chemist Vicki Colvin and Environmental Engineer Mark Wiesner and it includes chemists, physicists, environmental and civil engineers, chemical engineers and lately, two anthropologists. The center is one of 14 that were initially funded by NSF, modeled on their Science and Technology Center program, but focused in areas of interest in Nanotechnology. Of the 14 initial centers, and the handful of others recently funded, CBEN stands out as the only science and engineering center with any emphasis on human and environmental issues (see Box 1: NNI NSE Centers). 


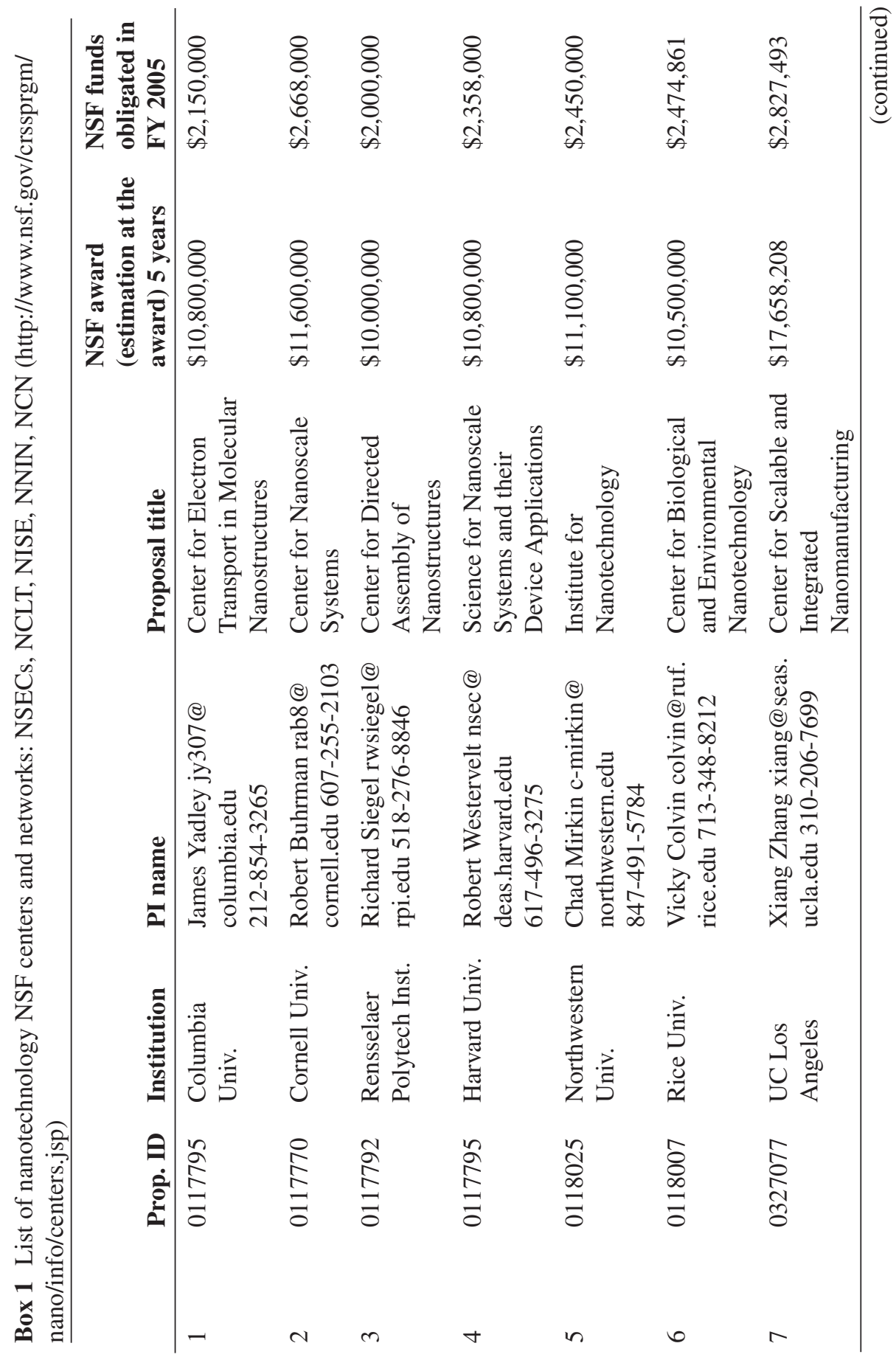




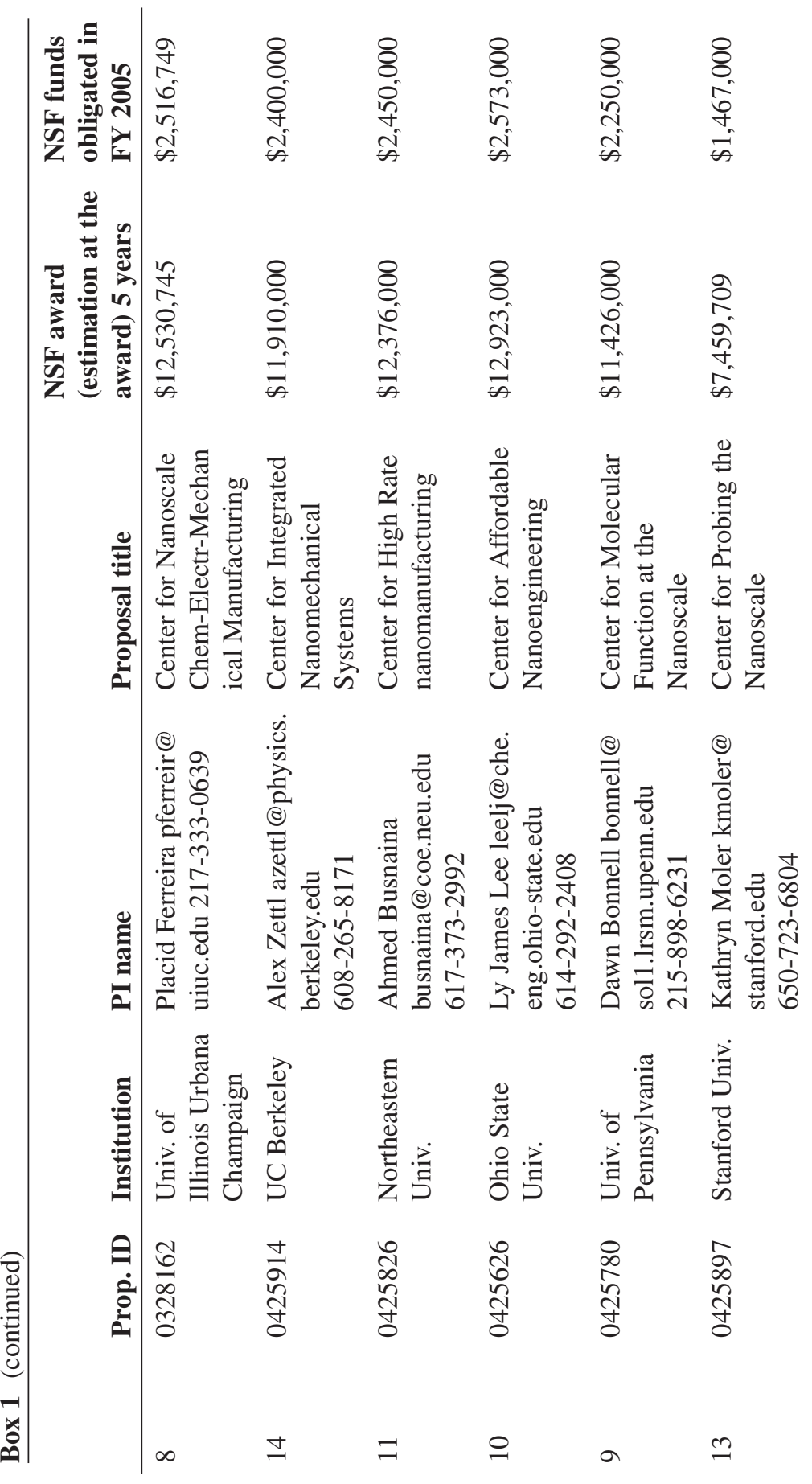




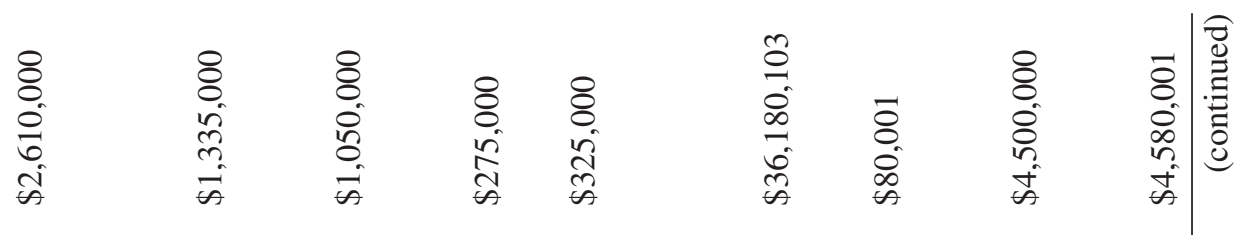

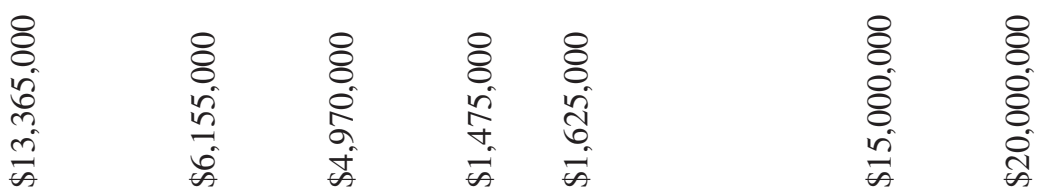

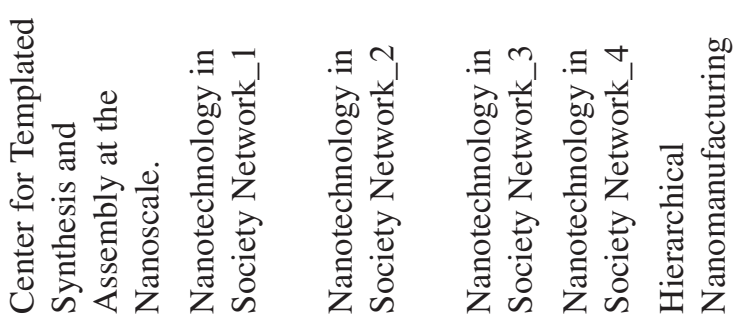

Uัँ

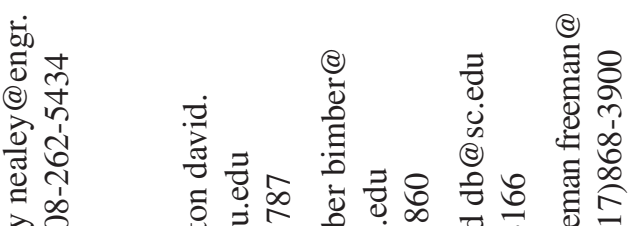

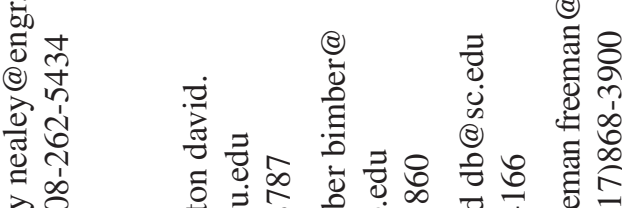

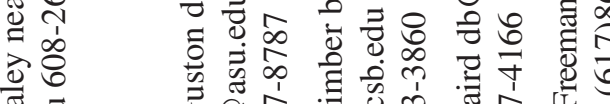

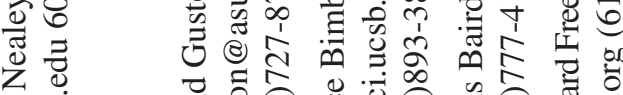

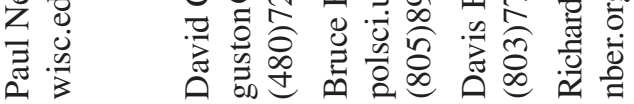

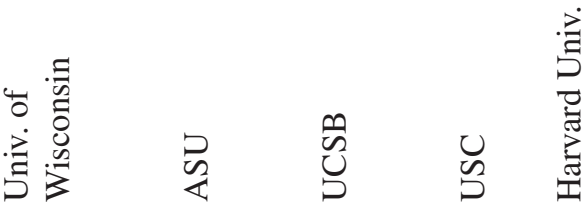

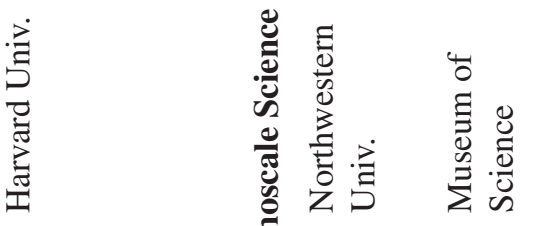

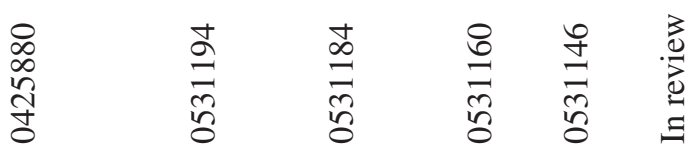

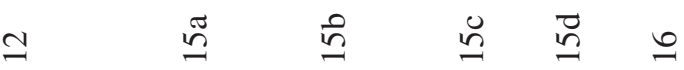

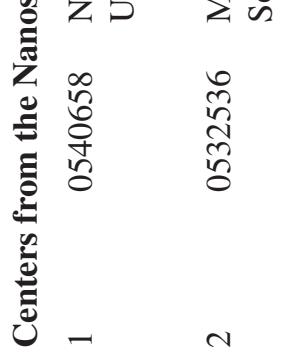




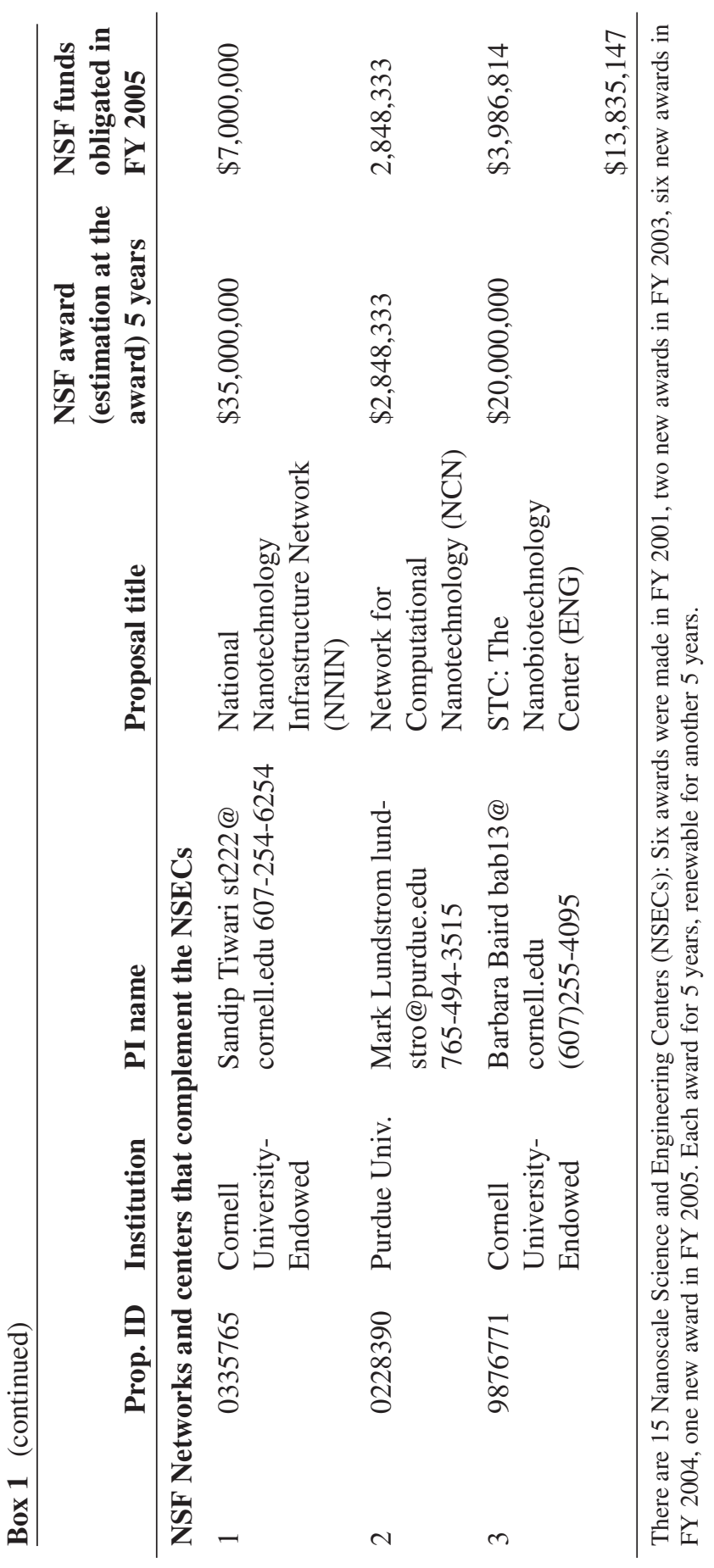


The trade-offs involved in making such a center happen are not insignificant, they will be explored in more detail in the third section.

CBEN, and the other centers like it, are NSF Centers whose mission is more complex than simply the performance of research. Unlike a simple grant for a research project, the center model assumes that research projects need to be precipitated in some way - and that rather than the NSF in DC attempting to second-guess the wide range of possible research directions in the area of science and technology, they might "outsource" some of that activity to focused centers. The centers, thus, are charged with promoting - and funding - research in their areas, locally, in the disciplinary sense, and usually in the regional sense (though many are also "networked" across many universities).

It is important to note, therefore, that both the NSF and CBEN are involved in the same kinds of "meta-theoretical" or "meta-research" attempts to define what constitutes research in nanotechnology. For many people who have been involved in nanotechnology, the period between 2000 and 2005 appears to have been one in which a large amount of money was available, resulting in a concomitant re-definition of a very wide variety of research as "nanotechnology". Nowotny et al. (2001) for instance, suggest that nanotechnology is a classic form of "weakly contextualized" science - precipitated in large part by political goals that involve ensuring national competitiveness in nanotechnology. The implication being that a very large number of people who claim to do nanotechnology are simply continuing research directions that long predate the NNI, and may have nothing to do with the presumptive core vision of nanotechnology.

While it may be the case that many scientists have done just such a thing, it does not, therefore, mean that there is no content to nanotechnology, and the existence of multiple centers (in addition to trade and industry associations, conferences, publications, and other standard organs of scientific practice) should be understood as an active transformation - possibly even creation - of the definition of nanotechnology. Indeed, prior to the funding of these centers, the most common definition of nanotechnology came from K. Eric Drexler and the Foresight Institute and their notion of bottom-up molecular manufacturing. Drexler and those who followed his vision were indeed very specific about what they suggested nanotechnology would encompass, and what it would not, citing various authorities along the way to bolster their case (Regis, 1996; Toumey, 2005).

Thus the creation of 14 diverse centers essentially inverted this situation by considerably broadening the various definitions of nanotechnology that circulate; this transformation was perceived by Drexler as the dilution and destruction of the vision of molecular manufacturing (Drexler, 2004). The success involved in creating the NNI was the failure in his eyes of focusing scientific energy on a specific problem. But for many new participants, this broadening and refocusing of the possible definitions of nanotechnology has been a welcome change, especially those made uncomfortable by the more radical and utopian fears and desires of Drexler and followers (Baum, 2003). Meanwhile, at least some philosophers and ethicists have busied themselves with the question of the distinctiveness of nanotechnology (Khushf, 2004; Dupuy, 2004a, b) 
The fact remains, however, that most of the NSF Centers in nanotechnology are devoted not only to scientific and technical work but to what might be called the supporting activity of defining nanotechnology, disseminating ideas about it, educating various publics and stakeholders, communicating with the media, and in general, trying to do more than simply promote research amongst scientists and engineers, but to build a constituency of support for the center's activities far beyond the laboratory. Indeed, the continued existence of these centers after the initial 5 years, will hinge on their importance to the University, or to funding agencies or corporate interests beyond the NSF.

How then, has CBEN been defining its activities? Because of the close relationship between the chemical industry and the chemical engineers on the Rice faculty, CBEN's self-presentation starts this way: "[CBEN] aims to shape nanoscience into a discipline with the relevance, triumphs, and vitality of a modern day polymer science." The reference point is strategic - it appeals to chemical engineers, and it sets the boundaries within which it is possible to imagine a definition of nanotechnology as a kind of materials science. The relationship that materials science has to issues of human health and environmental safety.

But CBEN is also aimed at something much more general, in terms of the theoretical disposition of its research - they refer to this as the "wet/dry interface":

Water, the most abundant solvent present on Earth, is of unique importance as the medium of life. The Center's research activities explore this interface between nanomaterials and aqueous systems at multiple length scales, including interactions with solvents, biomolecules, cells, whole-organisms, and the environment. These explorations form the basis for understanding the natural interactions that nanomaterials will experience outside the laboratory, and also serves as foundational knowledge for designing biomolecular/nanomaterial interactions, solving bioengineering problems with nanoscale materials, and constructing nanoscale materials useful in solving environmental engineering problems.

http://cben.rice.edu/about.cfm?doc_id $=4998$

This definition of CBEN's research distinguishes it from other centers and other research sites by defining it in terms of the interaction of environment and materials, with specific reference to the central role of water, which would be obvious to chemists and chemical engineers. However, there is also a very strategic trade-off hidden in this description. On the one hand, scientists interested in promoting nanotechnology perceive a risk that emphasizing the negative effects of nanomaterials might have grave consequences on future funding. As a result, many scientists, including Richard Smalley, have actively sought to downplay such research, and even in some cases, actively deter funding and research into the hazard and exposure risks of nanomaterials. By the same token, there is a perception among an equal number of nanoscientists (and corporate representatives as well) that ignoring such potential dangers is precisely what has led to major problems in the past (for instance, in DDT, paraquat, GM foods, or asbestos). Hence there are also a number of scientists vocally calling for more research, not less, on safety, toxicity and hazard/exposure risks.

The bargain that was struck in CBEN - a necessary bargain in order to get Richard Smalley involved - is clear in the definition of the research above. CBEN 
funds projects that research and test nanomaterials for biological and environmental use - and it does not simply study the risks that they may or may not present. Despite how it might appear, this trade-off is not disingenuous. The two principals primarily responsible for creating $\mathrm{CBEN}$ have conducted research that fits this profile precisely: Vicki Colvin, a chemist, has in fact conducted toxicity studies even though this is not her primary research focus (Colvin, 2003), and Mark Wiesner, an environmental engineer, has created new nanomaterials for use in water filtration and fuel cells (Wiesner et al., 2003). Hence CBEN has involved itself in both the nanotech-for-environment and the dangers-to-environment sides of this definition. It may be, in fact, that it was this bargain that gave CBEN its distinctiveness, a bargain by which toxicity and hazard studies were included insofar as they take a positive role in the promotion of the responsible creation of new materials.

Like all the NSF Nanotechnology centers, CBEN's mission is broader than only research. CBEN also has as part of its mission, various forms of outreach, education, and public relations work. CBEN's attempt to manage the image of nanotechnology is part of its "meta-research" activities; part of the activity of defining what nanotech is, who it benefits and who it might threaten. Most of the work of outreach, education and public relations was motivated implicitly, if not explicitly, by what researchers in the Public Understanding of Science call the "deficit model" of scientific literacy - that the public, whoever they are lacking some quantity of scientific information, without which they are unable to properly assess the work and meaning of modern science, and may even, in some cases (as when they are manipulated by popular novels like Michael Crichton's Prey or fear-mongering Drexlerian scenarios of grey-goo) become dangerous to the future life and funding of nanotechnology as a research science (Sturgis \& Allum, 2004). Education, research and public relations are therefore necessary to stem this tide of dangerous, false-thinking publics by increasing the quantity of scientific literacy in the world. CBEN is by no means alone in adopting this attitude, even if it has been widely critiqued. The result is that a significant focus of the small amount of social science research undertaken or promoted by $\mathrm{CBEN}$ is on the perception of the risks of nanotechnology - usually conceived of primarily as a consumer product, and not, despite the sophistication of CBEN's environmental focus, a systemic issue of production and planning. This approach raises the question of whether or not anthropologists would be more at home pursuing such research, defined in large part by the directors of CBEN, or more comfortable offering criticism of the questions and thereby risk being ignored. We return to this issue in the next section.

Within CBEN, and in many other circles of the nanotech world, the most dangerous publics (in terms of potential impact on the future of nanotechnology research) tend to be environmental advocates and activists, ranging from groups such as Environmental Defense and the National Resources Defense Council to the most learned and deeply critical, the ETC Group. As a result of attempting to understand the dangers posed by publics - especially these groups - CBEN directors formed a kind of institutional bud-growth: another center called the International Council on Nanotechnology (ICON). ICON is an institution co-funded and run by industry partners, CBEN, and various environmental advocacy stakeholder groups. 
It is intended to be as impartial as possible, serving only to facilitate the interests of the participating stakeholders. The corporations involved are those who simultaneously have some of the biggest goals for developing nanotechnology, such as the cosmetic company Loreal and chemical company DuPont - but they are also those with the deepest concerns about the management of the risk and hazard of new nanotech, like the Swiss Re reinsurance corporation, whose experience with the banning of GM foods in Europe made them hyper-sensitive to the problems of ignoring potential risks.

ICON was inaugurated in summer of 2005. The immediate need for ICON arose out of a desire to meet the potential publics halfway - but since "the public" as such has no secretary to call, and no email address, ICON effectively narrows down the definition of public to the stakeholders perceived to be most important to - or critical of - nanotechnology research. Coordinating various groups - university, industry (including not just manufacture, but as the case of Swiss Re makes clear, other kinds of corporate observers), environmental advocacy, activist and social movement groups - required some kind of "independent" organization. As of this writing, ICON has almost achieved that independence, but even given its forthright attempts to meet these publics halfway could not convince, for instance, Environmental Defense or ETC Group to join as official members. Nonetheless, the very existence of this kind of institution suggests that the configuration of science and society is changing - and that CBEN (and ICON) represents one of the most concerted experiments in identifying participants, risks, and potential problems well in advance of any real dissemination of nanomaterials or consumer goods associated with them, without giving up the core desire of scientists and engineers to pursue the discovery, synthesis and promotion of new materials and new technologies.

\section{Allotrope: Method}

Broadly speaking, one of the key reasons anthropologists (and other social scientists) might be interested in nanoscience and nanotechnology research is in order to test theories about the historically changing relationship between social and governmental institutions and scientific research. Pioneering work in the history of science, such as Shapin and Schaffer's Leviathan and the Air Pump has suggested that the interpenetration of the two is deeper and more complex than is usually assumed (Shapin \& Schaffer, 1989). Shapin and Schaffer detail how Hobbes political philosophy was also a theory of nature and natural process, and that Robert Boyles' experiments with an air pump within the brand new Royal Society were also political claims about relationship of knowledge to sovereignty.

Today, the relationship between forms of scientific knowledge and the social order they relate to is, if anything, vastly over-theorized. One can choose from theories of reflexive modernization (Beck et al., 1994; Lash \& Urry, 1994; Beck, 1992) actor network theory (Callon, 1986; Law, 1987; Latour, 1987), mode 1/mode 2 theory (Gibbons et al., 1994; Nowotny et al., 2001), triple helix (Etzkowitz \& Leydesdorff, 
1995, 1996) or co-production (Jasanoff, 2004, 2005) among just some of the more well known. Social scientists have an abundance of theories to draw on in order to explain the changing nature of the relationship in science and society in the recent past. But by the same token, this embarrassment of theoretical riches is accompanied by a relative poverty of methodological innovation. What sites, methods, techniques, questions, observations or participations should the interested anthropological observer be engaging in vis-à-vis nanotechnology? How does one go about asking questions, performing research that helps sort out these various theories, refine them or extend them? To whom does one talk, and about what exactly?

Anthropologists who are interested in these questions about the changing relation of science and society, and the meaning more generally of those changes for social theory and for human action, must devise ways to conduct empirical research given the tools and methods of ethnographic fieldwork. Broadly speaking, the goal of anthropological fieldwork is not so much to test, in a statistical fashion, whether these theories are correct; rather it is to go into the field with these theories and try to discover where they lead, and where they need to be refined or abandoned. That is to say, anthropologists generally are not interested in approaching the question of the impacts of science on society or vice versa independent of the theory (as a practice of statistical confirmation or disproval), but with theory-in-hand, as a practice of situated, embodied re-thinking of these theories - and this is what ethnographic fieldwork provides.

As this article suggests, one might begin this practice simply by landing in a specific site - in this case CBEN - and through participation and observation, come to some kind of understanding of the role and meaning of the actions of individuals engaged in this site. But this is too simple - CBEN as a site is both too specific (it does not "represent" nanotechnology) and too diverse and heterogeneous (there are dozens of labs and hundreds of projects under its purview). It is necessary to make some choices about what kinds of participation and what kinds of observation will help distinguish the essential from the accidental, or the unique and interesting from the ephemeral and quotidian. At this point, some reflection on the methodological conundrums of anthropology is useful in order to understand why some people in $\mathrm{CBEN}$ and some activities may be more appropriate than others for observation.

To begin with, however, it should be made clear that there are (at least) two distinctive kinds of activities that happen in CBEN, which it is necessary to describe in more detail. First, there are of course a number of different scientific experiments running at any moment - experiments expected to produce results related to nanotechnology, biology and environmental engineering and specifically to the use of nanomaterials for biological and environmental purposes or for hazard, exposure, or risk (including perception of risk). These experiments range from long-term investigations that aim at understanding the fundamental properties of new nanomaterials like buckyballs and quantum dots to relatively short-term experiments aimed at filling in gaps in knowledge to creative forms of analyzing existing data in order to answer open questions. Usually this activity includes senior and junior scientists, post-docs, grad students and undergraduates, technicians and staff. Often they occur between departments, and include faculty from diverse fields (always on 
the grants, occasionally in the lab meetings, sometimes on the published papers). Senior scientists, post docs and grad students do varying amounts of paper-writing and travel to conferences to promote and share results. Oversight from CBEN or the university is at a minimum, though it claims credit for the results (http://cben. rice.edu/research.cfm?doc_id $=5012$ ).

Second, there is the production of ideas about these experiments. CBEN actively promotes the direction of, sifting of, discussion and promotion of ideas, big and small, about the activities of CBEN and nanotechnology. Some are ideas about applications and implications of research results, some are about the clarification and dissemination of results, some are ideas that themselves need to be researched and confirmed or disconfirmed. In short, it is a kind of free form, intensive hypothesisgeneration activity (and hence, quite similar to the normal pursuits of the anthropologist, albeit in a different substantive context). It can also include ideas about the creation of standards, rules, voluntary ethics, and objectives for promoting these kinds of experiments; creation of institutions to do same (e.g. ICON); promotion, outreach, media management, reports and conferences, meetings, conversation and reading, etc. All of this is conducted in the context of a heavy emphasis on the definition of nanotechnology as a field, and in CBEN's case, a field that includes research on human health and environment.

There is of course a spectrum between these two kinds of activities. The dominant mindset of most participants in CBEN and CBEN-like institutions is a techno-methodological one, in which all questions (even those about objectives and goals) are best answered through some kind of scientific method, not through philosophical reflection or democratic deliberation. If members of CBEN suggest that, for instance, it is important to know whether the public knows anything about nanotechnology, this hypothesis is seen as something requiring (and worthy of) research funding in order to answer definitively whether or not the public has any knowledge of nanotechnology. It cannot stand as an assertion based on anecdote or observation, regardless of how extensive an individual's experience might be. However, as a result of this mindset, there emerges a very small, and very privileged sphere, within which it is in fact possible for certain members to speak with consequence about "nanotechnology" without needing to find some kind of demonstration or proof of an idea. This activity therefore looks more like the second, the production of ideas about nanotechnology, than the first, the experimentation and testing of issues related to nanotechnology. Obviously certain realms (such as the potential benefits of nanotechnology or issues perceived as social science questions) are easier to speak about without demonstration or proof than others.

Anthropologists interested in making sense of these two activities are confronted with a problem: these actors themselves appear to be interested in answering questions about the social, organizational, and cultural aspects of nanotechnology - what it is, what it could be, how it is related to people, institutions, societies, markets, and how the cultural authority of science can be made more responsive, responsible or ethically attuned. That is to say, a central preoccupation of at least the second form of activities engaged in at CBEN concern precisely the relationship of science 
and scientific knowledge to social order. These are questions anthropologists ask regularly, across the various subfields of the discipline, but they are here asked not by anthropologists or other observers (e.g. philosophy or sociology of science or science studies) but by the actors themselves, the putative objects of our analysis. And as I have suggested, they too find at least partial solace in the wealth of existing theorizations of a changing relationship between science and society, which help them make sense (to themselves) of their own actions and goals. Most scientists do this kind of "informal" research without recognizing that it is a form of research that could be conducted more "formally" by anthropologists, or science studies scholars.

For many anthropologists, this surprising recognition has become a theoretical and practical problem - most starkly evidenced by the question "what exactly to anthropologists add to this practice?" The remainder of this section reviews four modes of answering this question, four proposals for thinking about where, why and how to do fieldwork in emergent fields like nanotechnology.

First off, there is the by now classic genre of the laboratory study, made popular in the late 1970s and early 1980s (Latour \& Woolgar, 1979; Latour, 1987; Traweek, 1988; Collins, 1985; Pickering, 1992). Philosophers, sociologists and anthropologists, for various reasons have found themselves working amongst scientists, attempting to answer questions about their practice and about the vagaries of a sociology, or anthropology, of (scientific) knowledge (Fleck, 1981; Mannheim, 1955). In this frame, only the first of the two kinds of activities that occur in CBEN is explicitly observed - that of the scientific experiment itself. The anthropological "result" of such studies can vary depending on approach, from claims about social construction, to a focus on meaning and metaphor, to a concern with tacit knowledge, to a focus on lab infrastructure. A few studies in this area, especially that by Latour and Woolgar, recognize that both kinds of activities (the pursuit of experiments and the creation of ideas) occur in particular labs and institutions - especially in the distinction between the senior lab scientist (whose primary work consists of travel, grant-getting, ideagenerating and credit-building) and the junior level scientists, postdocs, grads students and technicians who perform the daily work of science.

Second, Holmes and Marcus (2005) have recently proposed the notion of "paraethnography" as a way of capturing the fact that many of the activities that people (such as those involved in CBEN) pursue are strangely similar to, and happen in the same times and spaces as those that anthropologists pursue (Holmes and Marcus study experts at the Federal Reserve and European Central Bank, and for them, highprofile persons like Alan Greenspan are "para-ethnographers" par excellence). That is to say, outside of the laboratory experiment, experts are involved in conferences and meetings, institution building, grant getting and organizing, conversation and reading, batting ideas around, focus groups and outreach, anecdotes and stories, public speaking, media relations, policy studies and promotion, testimony to congress - all things that anthropologists have often found themselves doing as part of their research. The "para-ethnographer" is the anthropologist's uncanny double, when the activities they engage in include investigation, reading, interview, survey, taking notes, offering critique and rethinking, etc. 
CBEN researchers, when they engage in the second kind of activities listed above (and this is especially true of the three main directors of the center), might be said to be doing something like fieldwork - but for putatively different purposes. It is precisely those people within CBEN granted the ability to reason about what nanotechnology is or could be (without needing to find or fund scientific demonstrations or proofs to do so), who would be considered the para-ethnographers in this framework. The implication of such an approach is strictly methodological - it suggests "where ethnography might literally go in fieldwork" by seeking out the sites of the anecdotal, the deliberative, or the non-technocratic forms of reasoning that nonetheless remain most powerful within highly rationalized and technocratic discourses (Holmes \& Marcus, 2003, p. 241).

In the case of CBEN, the ability to pronounce on nanotechnology takes a curious form: the directors are usually extremely careful when they speak about the risks of toxicity and exposure - and stick very closely to the available scientific literature. However, when they discuss the definitions, possibilities and potential benefits of nanotech, they are much freer in their discussion and explanation. The dominant language of risk assessment is an obvious outcome of this disparity but risk assessment applied only to the potential costs, not the benefits of nanotechnology. For the anthropologist, or science studies scholar, the interest is precisely in identifying where these gaps are productive: the places where nanotechnologists can effectively speak about nanotechnology in an anecdotal frame, and where they are forced to adopt a technical-rational one. Holmes and Marcus caution against becoming too embroiled in the technical-rational discussions, because they fear that by doing so, the work of anthropology will be rendered inaccessible and irrelevant to anthropology itself. They suggest that the core practice of offering critique and discussion relevant across the diverse anthropological fields is the first priority. They nonetheless recognize that it is the informants (such as those at CBEN or in nanotechnology generally) who will be most likely to understand and profit from a creative critique or rethinking of the relationship of science and society, or of the growth of institutions and ideas related to emergent sciences.

A third and similar approach to the para-ethnographic might be that advocated by Paul Rabinow, apropos of Niklas Luhmann: that of the "second order" observer of "first order" observers of society (Rabinow, 2003). This approach intends to lend some distance to both kinds of activities CBEN carries out, and to forestall some of the more immediate forms of criticism that anthropology or science studies might be tempted to immediately engage. Instead, it suggests a kind of provisional functionalism - an observational mode that is concerned with the goals and objectives of institutions such as CBEN or ICON, both manifest and latent, but which does not seek a strictly Weberian typology - precisely because second order observers are always someone else's first-order observers. What is interesting here is the comparison of such an approach applied to the first and second kinds of activities listed above. In the case of scientific experiments (which can also include social science research) the observation of the world is conducted in a strictly rationalized scientific manner (even if there are gaps and 
leakages of all kinds throughout the work, it is still organized within a clearly defined methodology and classification). The activity of the second kind, however, is much more mysterious, ad-hoc, uncoordinated, and unstructured. It is more than likely that the actors themselves do not know exactly what kinds of activities they engage in. All the more so in the field of "nanotechnology" where the wealth of complex interactions, the constantly changing goals and demands, and the tricky incompatibilities of disciplines and histories intertwine. It might be the case that CBEN is observing itself more carefully than anything soundly external to it. What "second order observation" seeks to add to this series of methodological possibilities, however, is the provisional nature of this distancing. Anthropologists need not relinquish the ability to speak with authority about nanotechnology and society, only to take a provisional stance of "adjacency" by which the perspectives - ostensively differently informed and more capable of critical analysis - can be compared with those of the 1st order observers (who may also be anthropologists or sociologists) of nanotechnology and society.

A fourth approach might be the more general field of an "anthropology of intellectuals" in which the old Weberian question of vocations are asked anew, or the more familiar sociology of knowledge/critique of ideology traditions are brought to bear here (Weber, 2004). A twist on this tradition is captured by Thomas Osborne (2004) in the notion of a "mediator" - that is, a kind of intellectual who is neither a "public intellectual" (e.g. talking head, policy advocate or activist) nor strictly speaking a scientist engaged in pure or basic research, but an individual interested in moving ideas from one sphere to another, or in creating the right environment (in terms of media, opinion, and scientific data) for certain ideas (Osborne, 2004). Here the activities of CBEN (of the second sort) might be made analogous to the activities of think tanks (such as the Brookings Institute or the Heritage foundation), even though their explicit goals are rarely to influence government policy or law-making. The promotion, direction, management, public facilitation of research ideas (if not results) is what "sets the stage" for the kinds of questions that get asked in labs and field studies. Seen in this light, the activity of CBEN is largely directed at making CBEN's definition of nanotechnology into something that drives research questions and experiments beyond what it funds itself. To a large extent, ICON can be seen as a way to promote this activity in an even more independent "stake-holder"-oriented manner.

These four methodological approaches are not mutually exclusive - but they do give an indication of one of the trickier aspects of anthropological research amongst scientists and experts. Are anthropologists capable of observing and participating in projects such as CBEN with sufficient detail and depth without sacrificing the ability to offer independent critique and re-thinking? How does one avoid, on the one hand, becoming co-opted into ("going native" in an older idiom) the project of such centers and research initiatives, and on the other, avoid becoming completely irrelevant through the willful attempt to maintain distance? In what ways can the practices and research of anthropologists, which are often deliberately unconventional in style and critical in philosophical terms, become part of the practice of organizations and centers where experts consider issues of the relationship of science and society? 


\section{Allotrope: Substance}

Methodological questions such as those raised above are most often a concern because of the clear disjunction between the subject matter of anthropology and that of its observed expert or elite subjects. Nanotechnology, for instance, appears on the surface to have almost no conceivable overlap with the putative subjects of study in anthropology. Particles of carbon that are less than $200 \mathrm{~nm}$ in size seem at first blush to be as far as possible from, for instance, issues of consanguinity in kinship or symbolic meaning in a religious ritual. In large part this is true, but it is nonetheless quite easy to identify some issues of technical and scientific detail that are related more or less directly to those of anthropological concern. In the case of CBEN, this issue is made all the easier by virtue of its explicit focus on the environment and human biology. Toxicity, environmental hazard and the potential for remediation or prevention through nanotechnology are all issues that have eminently social and human dimensions, and might well connect easily with the practices of anthropologists working in medicine and the environment.

For some scientists in CBEN, these same questions are also salient - but the normal organization of scientific and engineering research and funding does not facilitate their asking. An institute like CBEN is a rarity therefore, largely because the kinds of disciplinary questions that normally seen so central are subordinated to a set of concerns about shared objects: in this case human biology and the environment. This does not, however, mean that the work of scientists and engineers will naturally pursue these objects in some synthetic fashion - hence the need for both scientific work, and the work of producing ideas about it that CBEN directors participate in. Take for example, CBEN co-founder and environmental engineer Mark Wiesner.

Wiesner is an unusual scientist. A graduate of John's Hopkins Geography and Environmental Engineering department, Wiesner came to Nanotechnology accidentally (in much the same way the author did, largely because there was such a heavy emphasis on nanotechnology on the Rice campus), but it has created for him a completely novel approach, unusual in his own discipline and practice, as the opening epigraph illustrates. Wiesner's approach to environmental engineering has been transformed by nanotechnology, and in particular by the worldview in which nature is seen as inherently engineerable, from the bottom up. The idea of making pure water from scratch, as opposed to cleaning it of toxins and other harmful materials, is a nano-inspired mode of thinking - not a standard approach amongst environmental engineers.

However, for Wiesner, nanotechnology is not necessarily a revolutionary interdisciplinary science, but it is a field within which questions that have plagued environmental engineers and their precursors become exciting and novel once again.

Q: Does nanotechnology in your lab provides the sense that you're at the cutting edge of something, you're the leading edge, you're in the process of discovery?

A: Mmmm, I would say that it's not nanotechnology per se that has been a big stimulus in the group. I'd say that right now the most exciting sort of, you know, fast changing stuff that's going on has to do with understanding the environmental uses and properties of a new material, which is the fullerenes. All the other stuff is sort of interesting, but, um, it's been around in different forms. And, although we have some ideas about what we 
think is unique... I still think that right now it's just, well, nobody's ever looked at, you know, what a fullerene can absorb or how it interacts with water or why it structures itself in this way with other fullerenes.

Q: So that's the exciting part is these new materials

A: [Yeah] And people see it as the material that's gonna have important economic uses. And so, you say, well this is important stuff to work on because we're not-it's not like plastics that are everywhere right now-but it could be. And so, this really is going to be a material that we need to understand, you know we need to...if we know something about it now it's gonna make a difference for the future.

Getting to the point where he could study the interaction of fullerenes and water, or think about the properties, hazards or uses of fullerenes, however, has not been an easy task. Wiesner's involvement in CBEN was largely serendipitous: he was the one environmental engineer at Rice who seemed like the sort of person who might be interested in writing a grant to the NSF - and so was invited to do so by Vicki Colvin. And though the process was difficult, his participation and his insistence on studying the potentially dangerous aspects of nano-materials proved crucial to the funding of CBEN, as he explains:

When CBEN was finally funded, in December 2001, this was really, I believe, the first time anyone had articulated publicly the issue of not only how you can use nanotechnologies to do good things for the environment, but also what are the implications of these nanomaterials for the environment? ... Another interesting aspect of that whole process was that ... the EPA at the time was funding things like how can you do nanotechnology to clean up the environment? or how can you use nanotechnology to treat drinking water? But the implications thing hadn't come through, and so when we were writing a proposal, Vicki's original idea was that she wanted me to group together people that were going to do technologies along that line, where we would be using nanotechnology for good [laughter] And every time I'd write the evil part [laughter]... It'd keep getting kicked back, and I'd say well we didn't have enough room, I'll cross that out. And it was really difficult to keep [the issue of the implications of nanotechnology] in the proposal. But it finally went through, and by talking with one of the people that was actually on the review panel, who's now a faculty member in this department, I came to understand actually even at that time when we went in for the visit, that that aspect of it was really one of the key things-along with having a Nobel prize winner-that really set us apart, and one of the key things that got anything funded. So, it was very controversial to have it accepted, and sort of an afterthought, but it turned out to be really important in getting it funded. And the controversy didn't stop after it was funded. I mean, it's continued to be something that people don't really know what to do with it.

The trade-off visible in CBEN's self definition - as an entity that can pursue research both on the potential dangers of nanotechnology and the potential uses of nanotechnology "for good" stem from the confrontation of one set of research concerns, represented by Wiesner (the interest in the environmental properties of fullerenes, such as their mobility in water) and those of another, represented by chemists like Richard Smalley (research into the synthetic and creative possibilities of fullerenes). This confrontation results in the peculiar and unique definition of nanotechnology promoted by CBEN. For Wiesner, such research is in fact fundamental research - not the kind of thing that is subsequent to research on new applications, materials or possibilities, as he makes clear: 
One of the comments that came back on the proposal review for the Center, was "this is all too premature; this is all premature, we've got no nanochemistry industry, we have no idea what this stuff is. Why would you want to study this now?" And, the response to that is if you don't do it now a) when are you going to do it? And b) anything you do learn now, it's like a spaceship heading toward the moon, you know if you alter the trajectory just a little bit at the beginning it has huge impact down the line. And so, it's a very powerful time, even if you're not getting the full picture, to try to gather any information you can.

Perhaps ironically, even though Wiesner has fought to make the study of hazard and toxicity a core aspect of basic research in nanotechnology, his own research has not focused solely on this issue. Indeed, Wieser is one of the researchers who has most diligently pursued projects that fulfill the other side of the bargain - the desire to create novel nanomaterials that can be used in environmental engineering. Prior to the creation of CBEN, Wiesner had long been involved in collaboration with Andrew Barron on the creation of new kinds of nano-materials that could be used as membranes for filtration (specifically alumoxanes and ferroxanes). Wiesner's earlier work, before arriving at Rice had focused primarily on membrane science, but not with nano-materials, so Wiesner's collaboration with Barron allowed the two to explore areas of mutual interest that made use of new techniques and a new interest in nanoscale materials. For Barron, understanding the chemistry and synthesis of alumoxanes proved a challenging basic chemistry problem, while for Wiesner the potential use of such materials in order to filter fine particles from water proved a novel re-imagination of what environmental engineering could achieve in the area of Nanotechnology.

The approach of creating a membrane through the synthesis of nanomaterials requires something like a "nano worldview": rather than take existing materials and break them down into component parts and smash them together to form a membrane, Wiesner and Barron effectively created a material from scratch - a material whose properties and behaviors were more accurately theoretically understood and which could be explored using the visualization tools of nanotechnology (STM/ AFM, etc.), as well as the more conventional testing of materials conducted by environmental engineers. Furthermore, because the materials are so well understood, they led the two scientists to imagine other membrane-like uses, such as the creation of alumoxane and ferroxane fuel cells - something seemingly far afield from the concerns with filtration of water.

\section{Conclusion}

But how are water filtration and fuel cells also anthropological problems? How can fieldwork amongst scientists and CBEN directors be understood critically as a practice that may have wider implications for an anthropological or social theoretical understanding of science and society?

From one angle, the success of the research and technologies pursued by CBEN rests primarily on decisions that will be made elsewhere and by other people about 
the value of the environment, or the value of human safety - Wiesner and Barron's work is understood to be a demonstration of certain technical possibilities that are intended to influence those decisions, whether promoted directly or not. Human safety, in terms of water quality, is demonstrably possible, as are cleaner forms of energy production with fuel cells (which also have the production of pure water as a by-product). From this angle, the changing cultural authority and power of science are obvious subjects of anthropological interest. To whom are these inventions and discoveries meaningful? To whom are they promoted and for what purposes? Who is expected to understand the potential of such work, and what forms of rational response are expected, either by the scientists themselves or by decisionmakers or planners?

Wiesner himself, and many other scientists are acutely aware of the fact that merely demonstrating the possibility of human safety or energy efficiency are rarely sufficient to change any real practices in the world. Hence, an institution like CBEN does more than promote basic research - it can generate and promote ideas about this research that might set the stage for real changes. Whether or not it is more or less successful for doing so is one strong reason to observe it in action, as it makes the attempt; perhaps it means participating with these "para-ethnographers" as they go about investigating the values and practices that will help promote or deter what are understood to be better, safer, cleaner, or more feasible technical solutions; perhaps it means adopting a "second-order" point of view, in order to get at what these first order observers miss.

Yet seen from another angle, the creation of nanotechnology might simply serve the incessant demand for novel technologies, regardless of their effect on human health and the environment - that is, solely in order to satisfy certain economic demands in which growth, productivity, national or regional development, or international stature are tied to constant scientific and technical breakthroughs. In this light, it does not matter what kind of values the work of scientists and engineers are intended to serve - rather they are only valuable insofar as they can be translated into the terms of productivity and growth demanded by financial markets and businesspeople. CBEN might simply be a more efficient way to try out the maximum number of different routes, in a rush to identify profitable technologies. Even so, the critical approach of the anthropologist who can observe the constant interactions in such a setting can offer a critical view on this kind of relationship.

CBEN, and the scientists funded by it thus face a kind of puzzle concerning the cultural authority of science - and it is a puzzle that in some ways mirrors the puzzle faced by anthropologists who wish to study elites, experts or high-tech organizations and practices. It is a puzzle about the nature of the relationship between a critical scientific project - one in which the directions and values that underlie the practices are implicitly focused on issues of improving human health and safety through the investigation of alternatives to existing technologies, materials and chemicals.

CBEN offers a framework within which those pursuits are granted a provisional legitimacy, and a wider cultural authority than any single scientist might possess. And yet, in order to do this, it is necessary to risk co-optation, to risk creating new nanomaterials that may or may not be safe, may or may not be understood, and may 
or may not be responsibly used once discovered. Such scientific pursuits cannot be conducted solely in the voice of critical, defensive or precautionary research, that is to say, CBEN cannot simply be an institution that researches the potential risks and dangers of nanotechnology, but must also participate in the search for the novel and the undefined. This is not simply because CBEN and scientists serve other masters - whether the NSF or corporate dollars - but because this is in fact where the action is. The understanding of new materials and the invention of new uses and application is what gives the vocation of nanoscience and nanotechnology much of its momentum. Without this action, it becomes the mere bureaucratic accumulation of facts, devoid of the calling Weber so clearly identified as an essential component of the scientific mind. To ask scientists to occupy only the position of a caution is to prevent them from defining, contesting or arguing for the values that attach to new discoveries, new applications, or new materials, and to deny them the satisfaction of knowing that science can be used for good, as well as for evil.

By formalizing the insights that anthropology brings, and indeed, by making the "para-ethnographic" work of participants visible and tangible, anthropological fieldwork can help make good on this critical promise, if it is willing to take a parallel risk of participation. It is a common theme in the explanation of nanotechnology to insist that it is involved not only in an attempt to understand nature but to offer some kind of control as well; the same might be true of anthropology in this instance, it is not only an attempt to understand the social relations of science and implications of science, but to find novel ways of controlling them as well. Investigating the properties of the allotropes of fieldwork is a contribution to this endeavor.

\section{References}

Baum, R. (2003). Drexler and Smalley Make the Case For and Against 'Molecular Assemblers'. Chemical and Engineering News, 81(48), 37-42, available at http://pubs.acs.org/cen/ coverstory/8148/8148counterpoint.html

Beck, U. (1992). Risk Society: Towards a New Modernity. Trans. Mark Ritter. London: Sage.

Beck, U., A. Giddens, \& S. Lash (1994). Reflexive Modernization - Politics, Tradition and Aesthetics in the Modern Social Order. Cambridge: Polity Press.

Callon, M. (1986). Some Elements of a Sociology of Translation: Domestication of the Scallops and the Fishermen of St Brieuc Bay, in J. Law (ed.), Power, Action and Belief: A New Sociology of Knowledge. London: Routledge \& Kegan Paul.

Collins, H. M. (1985). Changing Order: Replication and Induction in Scientific Practice. Beverley Hills, CA/London: Sage. [Second Edition, with a new Afterword, Chicago, IL: University of Chicago Press, 1992.]

Colvin, V. (2003). The Potential Environmental Impact of Engineered Nanomaterials. Nature Biotech, 21(10), 1166-1170.

Drexler, K. E. (2004). Feynman to Funding. Bulletin of Science, Technology and Society, 24(21), 21-27.

Dupuy, J.-P. (2004a). L'irréalité de l'avenir et l'impuissance de l'éthique. Cas des nanotechnologies. In G. Nivat (éd.), Les limites de l'humain. 39èmes Rencontres Internationales de Genève, L'Age d'Homme, Genève, pp. 115-138.

Dupuy, J.-P. (2004b). Pour une évaluation normative du programme nanotechnologique. Annales des Mines (February 2004), 27-32. 
Etzkowitz, H. \& L. Leydesdorff (1995). Emergence of a Triple Helix of University-IndustryGovernment Relations. Science and Public Policy, 23, 279-286.

Etzkowitz, H. \& L. Leydesdorff (eds.) (1996). Universities and the Global Knowledge Economy: A Triple Helix of University-Industry-Government Relations. Book of Abstracts. Amsterdam: University of Amsterdam, $169 \mathrm{pp}$.

Fleck, L. (1981). Genesis and Development of a Scientific Fact. Chicago, IL: University of Chicago Press.

Gibbons, P., C. Limoges, H. Nowotny, S. Schwartzmann, P. Scott (1994). The New Production of Knowledge: The Dynamics of Science and Research in Contemporary Societies. Thousand Oaks, CA: Sage.

Gupta, A. \& J. Ferguson (1997). Culture, Power, Place: Explorations in Critical Anthropology. Durham, NC: Duke University Press.

Gupta, A. \& J. Ferguson (2002). Anthropological Locations: Boundaries and Grounds of a Field Science. Berkeley, CA: University of California Press.

Holmes, D. \& G. Marcus (2005). Cultures of Expertise and the Management of Globalization: Toward the Re-Functioning of Ethnography, in A. Ong \& S. J. Collier (eds.), Global Assemblages: Technology, Politics, and Ethics As Anthropological Problems. Oxford: Blackwell, pp. 235-252.

Jasanoff, S. (ed.) (2004). The Idiom of Co-Production. States of Knowledge: The Co-production of Science and the Social Order. Routledge: London.

Jasanoff, S. (2005). Designs on Nature: Science and Democracy in Europe and the United States. Princeton, NJ: Princeton University Press.

Khushf, G. (2004). A Hierarchical Architecture for Nano-scale Science and Technology: Taking Stock of the Claims About Science Made by Advocates of NBIC Convergence. In D. Baird, A. Nordmann, \& J. Schummer (eds.), Discovering the Nanoscale. Amsterdam: IOS Press, pp. 21-33.

Lash, S. \& J. Urry (1994). Economies of Signs and Space. London: Sage.

Latour, B. (1987). Science in Action: How to Follow Scientists and Engineers Through Society. Cambridge, MA: Harvard University Press.

Latour, B. \& S. Woolgar (1979). Laboratory Life: The Social Construction of Scientific Facts. Los Angeles, CA/London: Sage.

Law, J. (1987). Technology and Heterogeneous Engineering: The Case of Portuguese Expansion, in W. E. Bijker, T. P. Hughes, \& T. J. Pinch (eds.), The Social Construction of Technological Systems: New Directions in the Sociology and History of Technology. Cambridge, MA: MIT Press.

Mannheim, K. (1955). Ideology and Utopia: An Introduction to the SOCIOLOGY (740) of Knowledge. New York: Harvest Books.

Marcus, G. (1995). Ethnography in/of the World System: The Emergence of Multi-Sited Ethnography. Annual Review of Anthropology, 24, 95-117.

Marcus, G. (1998). Ethnography Through Thick and Thin. Princeton, NJ: Princeton University Press.

Marcus, G. \& M. Fischer (1986). Anthropology as Cultural Critique: An Experimental Moment in the Human Sciences. Chicago, IL: University of Chicago Press.

Nowotny, H., P. Scott, et al. (2001). Rethinking Science: Knowledge and the Public in an Age of Uncertainty. Cambridge: Polity Press.

Osborne, T. (2004). On Mediators: Intellectuals and the Ideas Trade in the Knowledge Society. Economy and Society, 33(4) (November): 430-447.

Pickering, A. (1992). Science as Practice and Culture. Chicago, IL: University Of Chicago Press.

Rabinow, P. (2003). Anthropos Today: Reflections on Modern Equipment. Princeton, NJ: Princeton University Press.

Regis, E. (1996). Nano: The Emerging Science of Nanotechnology. Boston, MA: Back Bay Books.

Shapin, S. \& S. Schaffer (1989). Leviathan and the Air-Pump. Princeton, NJ: Princeton University Press.

Stone, J. (n.d.) Anthropology and the Human Dimensions of Nanotechnology.... Manuscript, presented at the (2005). American Anthropological Association, on file with author.

Sturgis, P. \& N. Allum (2004) Science in Society: Re-evaluating the Deficit Model of Public Attitudes. Public Understanding of Science, 13(1), 55-74. 
Toumey, C. (2005). Apostolic Succession. Engineering and Science, 68(1, 2), 16-23, available at pr.caltech.edu/periodicals/EandS/articles/LXVIII1_2/Feynman.pdf

Traweek, S. (1988). Beamtimes and Lifetimes: The World of High Energy Physicists. Cambridge, MA: Harvard University Press. Paperback edition published in 1992 and reprinted in 1995.

Weber, M. (2004). The Vocation Lectures: Science as a Vocation, Politics as a Vocation. Edited and with introduction by D. Owen and T.B. Strong Tr. R. Livingstone. Indianapolis, IN: Hackett publishing [1917].

Wiesner, M., with M. M. Cortalezzi, J. Rose, G. F. Wells, J. Y. Bottero, A. R. Barron (2003). "Ceramic Membranes Derived from Ferroxane Nanoparticles: A New Route for the Fabrication of Iron Oxide Ultrafiltration Membranes." Membrane Science, 227, 207-217.

\section{Interviews}

Interview with Mark Wiesner, April 12, 2004, Rice University. 